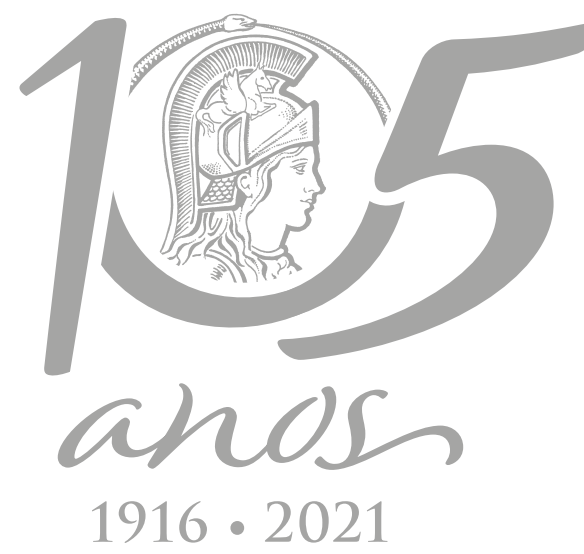

\title{
Hydrogen production by Enterobacter sp. LBTM 2 using sugarcane bagasse hemicellulose hydrolysate and a synthetic substrate: understanding and controlling toxicity
}

\author{
IVON M. CAMPOS, JOSE AUGUSTO ZOREL, MARILIA MENEGATTO, FLAVIANE SILVA, \\ OSCAR F.H. ADARME, MARINA TONUCCI, BRUNO E.L. BAÊTA, SÉRGIO F. AQUINO \& \\ SILVANA Q. SILVA
}

\begin{abstract}
Sugars released by thermochemical pretreatment of lignocellulosic biomass are possible substrate for hydrogen production. However, the major drawback for bacterial fermentation is the toxicity of weak acids and furan derivatives normally present in such substrate. This study aimed to investigate the metabolism involved in hydrogen production by the isolate Enterobacter LBTM2 using 10, 20 and 30-fold diluted synthetic ( $\mathrm{SH}$ ) and sugarcane bagasse hemicellulose ( $\mathrm{SBH}$ ) hydrolysates. In addition, the effects of acetic acid, formic acid and furfural on the bacterial metabolism, as well as detoxification of SBH with activated carbon and molecularly imprinted polymers on the hydrogen production were assessed. The results showed the best hydrogen yield was 0.46 mmol $\mathrm{H}_{2} / \mathrm{mmol}$ sugar for 20-times diluted $\mathrm{SH}$, which was 2.3-times higher than obtained in SBH experiments. Bacterial growth and hydrogen production were negatively affected by $0.8 \mathrm{~g} / \mathrm{L}$ of acetic acid when added alone, but were totally inhibited when formic acid $(0.4 \mathrm{~g} / \mathrm{L})$ and furfural $(0.3 \mathrm{~g} / \mathrm{L})$ were also supplied. However the maximum hydrogen production of $\mathrm{SBH} 20$ has duplicated when $3 \%$ of powdered activated carbon was added to the SBH experiment. The results presented herein can be helpful in understanding the bottlenecks in biohydrogen production and could contribute towards development of lignocellulosic biorefinery.
\end{abstract}

Key words: acetic acid, activated carbon, biorefinery, fermentation, molecularly imprinted polymers, xylose.

\section{INTRODUCTION}

Fossil fuel demands, population growth and environmental pollution create a need for new alternative energy sources which are both environmentally friendly and renewable. Hydrogen is a biofuel that can be produced by fermentative microorganisms and has several advantages, such as carbon-free biofuel and greater heat capacity (in mass terms), compared to conventional fossil fuels or even other biofuels (Bielen et al. 2013). Therefore, it is considered a cleaner energy, as its combustion generates only water, and can be produced from virtually any type of biomass (e.g. agricultural, forestry and food industry wastes) (Nissilã et al. 2014, Gonzales et al. 2016). Lignocellulosic biomass is an interesting option for producing energy, especially because it is readily available at low cost, abundant and easily accessible. Furthermore, it does not compete with food and feed applications, contributes to reduce greenhouse gas emissions and comes from different sources such as sugarcane, rice, wheat, 
corn and wood (De Bhowmick et al. 2018). In addition, lignocellulosic biomass, which is composed by cellulose, hemicellulose and lignin, have a great potential for bioenergy generation. Nevertheless, a pretreatment step, such as thermochemical process, is necessary to release C5 and C6 sugars (mainly glucose, xylose, arabinose) which can be further used by fermentative bacteria (De Bhowmick et al. 2018, Silva et al.2019, de Sá et al.2020). However, a major side-effect of thermochemical biomass treatment is the co-generation of inhibitory compounds to metabolism of several microbial species. Among the negative effects of these compounds on microbial performance, the following can be highlighted: perturbations in the cell membrane function; induction of reactive oxygen species production; contribution to decrease in protein and RNA synthesis; DNA damage; inhibition of glycolysis and/or fermentative enzymes; and consequent reduction in the yield as well as productivity of biofuels and other metabolites (Mills et al. 2009). The cell wall composition, the nature of lignocellulosic material and the type of pretreatment determine the inhibiting compounds which are produced (Chandel et al. 2013). These inhibitors can be classified into three main groups: furan derivatives (i.e. furfural and 5-hydroxymethylfurfural), produced by dehydration of pentoses and hexoses; weak acids, mainly acetic acid formed by hydrolysis of acetyl groups linked to the heteropolysaccharides of hemicellulose; and phenolic compounds resulting from solubilization of lignin (Lee et al. 2015). To overcome the issues related to the inhibitory compounds in lignocellulosic hydrolysates, some techniques for detoxifying the hydrolysates have been reported, including physical (evaporation and membrane separation), chemical (activated carbon treatment, ion exchange, neutralization and organic solvent extraction), and biological treatment (laccase or peroxidase) (Mills et al. 2009, Sivagurunathan et al. 2017). Activated carbon has been used to detoxify lignocellulosic hydrolysates due to its relatively low cost and the fact that this adsorbent is widely commercialized for removal of toxicants from water and effluents worldwide. Amongst the adsorbents that can be used for detoxifying hydrolysates, the molecularly imprinted polymers (MIPs) seem to be an interesting material due to their intrinsic features such as high selectivity, high adsorption capacity, relatively low cost and easy synthesis (Tarley et al. 2005, Shahar \& Mandler 2016). In summary, MIPs are synthetic adsorbent materials that have artificially generated recognition sites using the target adsorbate as template. It is a porous polymeric matrix of highly crosslinked three-dimensional structure containing microcavities with the selective adsorption sites. Such material is capable of selectively binding to a target molecule preferentially to other compounds present in the medium (Tarley et al. 2005, Shahar \& Mandler 2016). As an example, MIPs have been used to recover volatile fatty acids from anaerobic effluents (Tonucci et al. 2019). Therefore, understanding and controlling the effects of inhibitory compounds on hydrolysate sugar fermentation is essential to improve biofuel production. In this present study, the effects of furfural, formic and acetic acids on hydrogen production by dark fermentation in synthetic and real sugarcane bagasse hemicellulose hydrolysate were comparatively evaluated using the newly isolated Enterobacter sp. LBTM 2 as hydrogen producer. Fermentation was monitored on the basis of carbon consumption, degradation of inhibitors and accumulation of fermentative products (volatile fatty acids) in order to elucidate the hydrogen production pathway and the effects of inhibitory chemicals. In addition, adsorptive detoxification methods based on 
activated carbon and MIPs were applied in a sugarcane bagasse hemicellulose hydrolysate as an attempt to improve hydrogen production.

\section{MATERIALS AND METHODS}

\section{Bacterial strain and sugarcane bagasse hydrolysate}

The Enterobacter sp. LBTM 2 used in this study was first isolated in Eosin Methylene Blue Agar from a sewage sludge sample enriched with $10 \%$ sugarcane hemicellose hydrolysate and under anaerobic conditions (E. Duarte, unpublished data). The strain was identified by sequencing $16 \mathrm{~S}$ rDNA in combination with biochemical tests, including the capacity for anaerobic grow in arabinose and xylose (E. Duarte, unpublished data). The sequence was submitted to NCBI Gen Bank under accession number MW480239.

The sugarcane bagasse hemicellulose hydrolysate was obtained by a hydrothermal pretreatment according to procedures previously optimized as follows: $185^{\circ} \mathrm{C}$ for 35 minutes, 10.22 bar of pressure and with a solid to liquid ratio of 1:6 (g/mL) (Baeta et al. 2016). The overall and average composition of the hydrolysate was given by $2 \mathrm{~g} / \mathrm{L}$ glucose, $12 \mathrm{~g} / \mathrm{L}$ xylose, $0.6 \mathrm{~g} / \mathrm{L}$ arabinose, $4 \mathrm{~g} / \mathrm{L}$ formic acid, $8 \mathrm{~g} / \mathrm{L}$ acetic acid, $3 \mathrm{~g} / \mathrm{L}$ furfural and $1.5 \mathrm{~g} / \mathrm{L}$ of 5-hydroxymethylfurfural (5-HMF) (Baeta et al. 2016).

\section{Fermentation experiments}

All experiments were performed in $280 \mathrm{~mL}$ fermentation glass bottles with $150 \mathrm{~mL}$ working volume. The mineral medium (MM) was composed of $3.4 \mathrm{~g} / \mathrm{L} \mathrm{K}_{2} \mathrm{HPO}_{4}, 1.3 \mathrm{~g} / \mathrm{L} \mathrm{KH}_{2} \mathrm{PO}_{4}$, $2.0 \mathrm{~g} / \mathrm{L}\left(\mathrm{NH}_{4}\right)_{2} \mathrm{SO}_{4}, 0.005 \mathrm{~g} / \mathrm{L} \mathrm{FeSO}{ }_{4} .7 \mathrm{H}_{2} \mathrm{O}, 0.2$ $\mathrm{g} / \mathrm{L} \mathrm{MgSO}{ }_{4} .7 \mathrm{H}_{2} \mathrm{O}, 0.02 \mathrm{~g} / \mathrm{L} \mathrm{CaCl} 2.2 \mathrm{H}_{2} \mathrm{O}, 0.25 \mathrm{~g} / \mathrm{L}$ $\mathrm{NaHCO}_{3}$, and $1 \mathrm{~g} / \mathrm{L}$ yeast extract. The $\mathrm{pH}$ of the medium was initially adjusted to 6.5 with $1 \mathrm{M}$ $\mathrm{HCl}$. Each glass bottle was sealed with a butyl rubber stopper, degassed with nitrogen gas for 1 minute and then sterilized at $121^{\circ} \mathrm{C}$ for $15 \mathrm{~min}$. All experiments were inoculated with $0.02 \mathrm{~g} / \mathrm{L}$ (cell dry weight) of Enterobacter sp. LBTM 2. Triplicate batch experiments were carried out at 35으 and 180 rpm for 24 hours.

A comparative assay was performed with two hemicellulosic hydrolysate solutions: a sugarcane bagasse hemicellulose hydrolysate (SBH) described above, and a synthetic hydrolysate $(\mathrm{SH})$ composed of hemicellulosic sugars (glucose, arabinose, xylose) in mineral medium at the same concentrations verified in the SBH (Table I). Both solutions were investigated at 10-, 20- and 30-fold dilutions in MM, since preliminary tests (data not shown) indicated that Enterobacter sp. LBTM 2 could not grow without SBH dilution. Experiments aiming to investigate the individual and combined effects of furfural (FF), acetic acid (HAC) and formic acid (FA) on hydrogen production were also carried out. These three compounds were added into 10-fold diluted synthetic hydrolysate (SH10) test flasks at the same concentration found in the 10-fold diluted sugarcane bagasse hemicellulose hydrolysate (Table I).

Detoxification experiments with activated carbon and MIP were evaluated at the SBH2O test. Powdered Activated Carbon (PAC) (ref. C1012.06.AH Synth ${ }^{\circledR}$ ) was added to 3 and $4 \%$ $(\mathrm{w} / \mathrm{v})$ of the total reaction volume. MIP were synthesized using the bulk polimerization method according to procedures presented elsewhere (Tonucci et al. 2019). Briefly, the synthesis employed methacrylic acid (MMA) as monomer, chloroform:DMSO as porogenic solvent, 2,2'-azoisobutyronitrile (AIBN) as radical initiator, trimethylolpropane-trimethacrylate (TRIM) as crosslinking reagent and isovaleric acid (i-HVa) as template (Tarley et al. 2005). The synthesized MIP was tested at concentrations of $4.6 \%$ and $6.2 \%$. Both adsorbent materials tested (MIP and PAC) were added directly to the 
Table I. Experimental conditions of each experiment and Gompertz parameters for hydrogen production by Enterobacter sp. LBTM2.

\begin{tabular}{|c|c|c|c|c|c|c|c|c|c|c|c|c|c|}
\hline \multicolumn{2}{|c|}{ Experiment } & \multicolumn{7}{|c|}{ Composition (g/L) } & \multicolumn{4}{|c|}{$\begin{array}{c}\mathrm{H}_{2} \text { Gompertz's kinetic } \\
\text { parameters }\end{array}$} & \multirow{2}{*}{ Yielc } \\
\hline Condition & $\begin{array}{l}\text { Dilution } \\
\text { Factor }\end{array}$ & Glu & Xyl & Arab & FA & HAC & $\mathbf{F F}$ & 5-HMF & $\mathrm{H} 2$ & $\mathbf{R m}$ & $\lambda$ & $\mathbf{R}^{2}$ & \\
\hline $\mathrm{SH} 10$ & 10 & 0.3 & 1.5 & 0.2 & 0 & 0 & 0 & 0 & 0.21 & 0.07 & 3.6 & 0.9998 & 0.15 \\
\hline $\mathrm{SH} 20$ & 20 & 0.2 & 0.6 & 0.05 & 0 & 0 & 0 & 0 & 0.33 & 0.08 & 3.1 & 0.9974 & 0.46 \\
\hline $\mathrm{SH} 30$ & 30 & 0.1 & 0.4 & 0.02 & 0 & 0 & 0 & 0 & 0.14 & 0.03 & 3.4 & 0.9963 & 0.3 \\
\hline SBH10 & 10 & 0.2 & 1.21 & 0.06 & 0.4 & 0.8 & 0.3 & 0.16 & 0 & 0 & 0 & 0 & 0 \\
\hline SBH2O & 20 & 0.1 & 0.75 & 0.10 & 0.2 & 0.4 & 0.15 & 0.08 & 0.15 & 0.023 & 3.0 & 0.9914 & 0.2 \\
\hline SBH30 & 30 & 0.07 & 0.5 & 0.07 & 0.15 & 0.3 & 0.1 & 0.05 & 0.14 & 0.021 & 1.1 & 0.9945 & 0.3 \\
\hline SH10FF & 10 & 0.3 & 1.5 & 0.2 & 0 & - & 0.1 & 0 & 0.22 & 0.061 & 6.4 & 0.9945 & 0.15 \\
\hline $\mathrm{SH} 10 \mathrm{HAC}$ & 10 & 0.3 & 1.5 & 0.2 & 0 & 0.8 & 0 & 0 & 0.10 & 0.032 & 5.8 & 0.9984 & 0.11 \\
\hline SH10FA & 10 & 0.3 & 1.5 & 0.2 & 0.45 & 0 & 0 & 0 & 0.42 & 0.053 & 3.0 & 0.9903 & 0.27 \\
\hline SH10FF/HAC/FA & 10 & 0.3 & 1.5 & 0.2 & 0.45 & 0.8 & 0.3 & 0 & 0 & 0 & 0 & 0 & 0 \\
\hline SBH20 AC 3\% & 20 & 0.1 & 0.75 & 0.10 & 0.2 & 0.4 & 0.15 & 0.08 & 0.32 & 0.021 & 5.1 & 0.9954 & 0.44 \\
\hline SBH2O AC 4\% & 20 & 0.1 & 0.75 & 0.10 & 0.2 & 0.4 & 0.15 & 0.08 & 0.27 & 0.024 & 5.3 & 0.9994 & 0.33 \\
\hline $\begin{array}{l}\text { SBH20 MIP } \\
4.6 \%\end{array}$ & 20 & 0.1 & 0.75 & 0.10 & 0.2 & 0.4 & 0.15 & 0.08 & 0.16 & 0.019 & 3.8 & 0.9988 & 0.22 \\
\hline $\begin{array}{l}\text { SBH20 MIP } \\
6.2 \%\end{array}$ & 20 & 0.1 & 0.75 & 0.10 & 0.2 & 0.4 & 0.15 & 0.08 & 0.15 & 0.018 & 19.5 & 0.9909 & 0.21 \\
\hline
\end{tabular}

SH: synthetic hydrolysate; SBH: sugarcane bagasse hemicellulose hydrolysate; FF: fufural; HAc: acetic acid; FA: formic acid; Glu; glucose; Xyl: xylose; Arab: arabinose; HMF: hydroxymethylfurfural; AC: activated carbon; MIP: molecularly imprinted polymer; H2: maximum production $\left(\mathrm{mmol}_{2}\right)$; Rm: production rate ( $\mathrm{mmol} \mathrm{H}_{2} /$ hour); $\lambda$ : lag phase (hour); R2: adjusted coefficient of determination; Yield $\left(\mathrm{mmolH}_{2} / \mathrm{mmol}\right.$ substrate).

fermentation glass bottles and remained inside until the end of the process (24h).

\section{Experimental monitoring}

Bacterial growth was measured based on absorbance analysis at $550 \mathrm{~nm}\left(\mathrm{OD}_{550}\right)$ in a UV/ visible spectrophotometer (spectrum). The concentration of substrates (glucose, xylose and arabinose), fermentation products (formic, acetic, propionic, isobutyric, butyric, valeric and isovaleric acids), and furfural, were analysed by high-performance liquid chromatography equipment (HPLC) (Shimadzu, model CTO-30A), equipped with a refraction index detector (Shimadzu, RID-6A) and UV-VIS detector (Shimadzu, model SPD-10AV). An Aminex HPX$87 \mathrm{H}$ column (300 x $7.8 \mathrm{~mm}$ Bio-Rad) and a C18 precolumn (Bio-Rad) were used. Chromatographic separations were performed at 55으 $\mathrm{C}$ sing sulfuric acid ( $5 \mathrm{mmol} / \mathrm{L}$ ) as a mobile phase at a constant flow rate of $0.6 \mathrm{~mL} / \mathrm{min}$.

For hydrogen production determination, the pressure in the headspace of the flasks was measured with a manometer and the gases produced were sampled using a gastight glass syringe (Hamilton). Subsequently, 
the gas composition was measured by gas chromatography using a Shimadzu GC, model 2014/ TCD equipped with the CP-Molsieve 5A and CP-Pora BOND Q columns. Nitrogen at a flow rate of $273.8 \mathrm{~mL} / \mathrm{min}$ was used as carrier gas.

The modified Gompertz model, as showed in Eq. (1), was employed to fit the experimental data of $\mathrm{H}_{2}$ accumulation, lag phase and maximum production rate:

$$
H 2=H * e^{-e^{(R m * e / H) *(\lambda-t)+1}}
$$

where $\mathrm{H} 2$ is the maximum hydrogen production ( $\left.m m o l ~ H_{2}\right), \mathrm{H}$ is the hydrogen production, $\mathrm{Rm}$ is the maximum hydrogen production rate $(\mathrm{mmol}$ $\mathrm{H}_{2}$ /hour), $\lambda$ is the lag phase time (hour), $\mathrm{t}$ is the incubation time (hour) and e is the Euler's number (2.71828).

\section{RESULTS}

In order to compare bacterial growth and metabolism in the sugarcane bagasse hemicellulose hydrolysate and in the synthetic hydrolysate, a batch experiment with Enterobacter sp. LBTM 2 was monitored as well as concentration of substrates and products during fermentation. Growth under synthetic hydrolysate $(\mathrm{SH})$ conditions revealed that biomass gain and growth rates were different and apparently inversely proportional to the dilutions, although a similar exponential phase of $6 \mathrm{~h}$ was observed (Figure 1a). The highest microbial density was observed at the lowest $\mathrm{SH}$ dilution experiment (SH10). This suggests that bacterial growth in both the $\mathrm{SH} 20$ and SH30 experiments was limited by low substrate availability due to substrate dilutions (see Table I for sugars concentration in each experiment). In fact, after 8 h of fermentation, neither residual xylose (the major sugar in the hydrolysate), nor arabinose and glucose were detected at SH2O and SH3O experiments (Figure 2b and 2c), whereas at SH10 xylose supported the growth throughout the stationary stage (Figure 2a). On the other hand, dilution of the sugarcane bagasse hemicellulose hydrolysate $(\mathrm{SBH})$ was necessary to ensure bacterial growth, since no cell growth was observed for SBH10 (Figure 1a). In general, a similar maximum cell density was observed for SBH at 20- and 30-times diluted
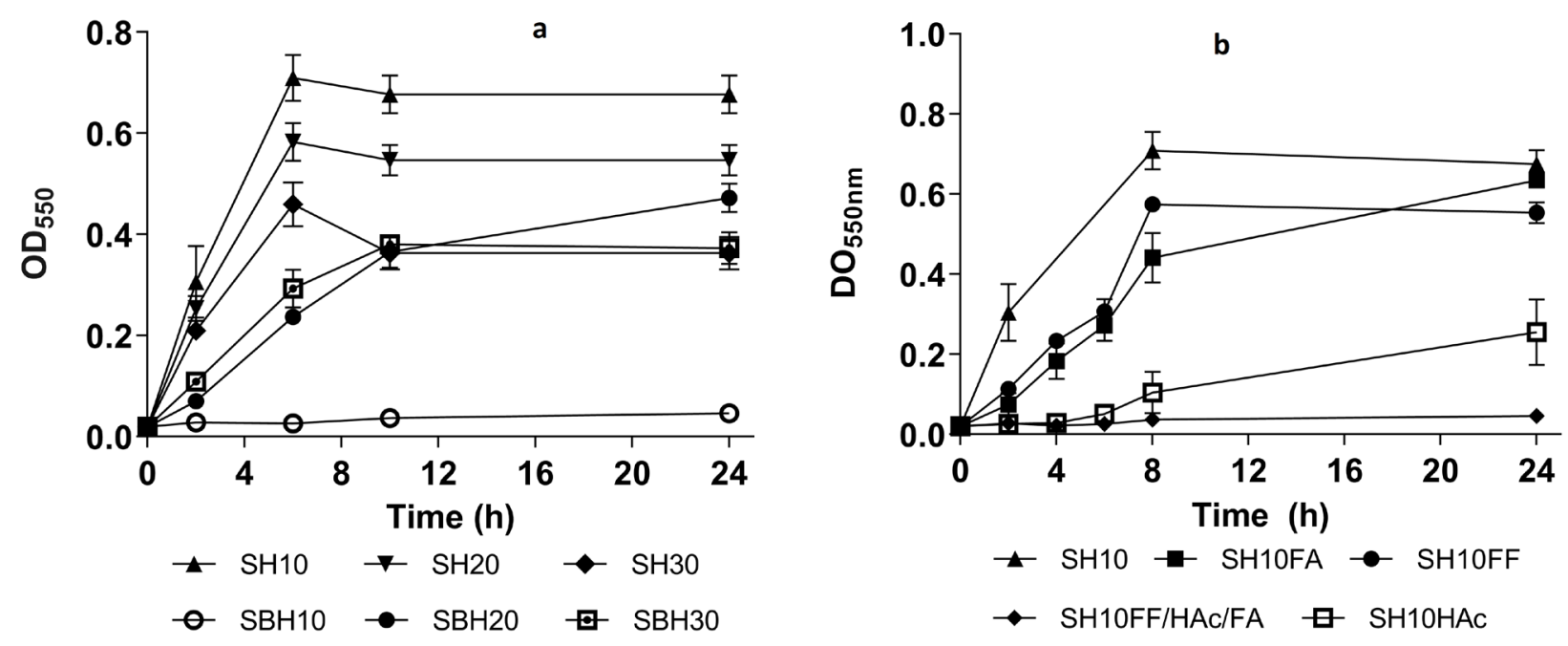

Figure 1. a) Enterobacter sp. LBMT2 growth in sugarcane hydrolysates diluted 10, 20 and 30 times (synthetic - SH and sugarcane bagasse hemicellulose hydrolysate - SBH); b) Effect of formic acid (FA), furfural (FF), acetic acid (HAC) and a mixture of them (FA/FF/HAC) on Enterobacter sp. LBMT2 growth in SH10 experiments. 
experiments. However, in these conditions the growth rate of $\mathrm{SBH}$ was slower than $\mathrm{SH}$, probably caused by the presence of microbial metabolism inhibitors in the SBH.

To investigate the role of furfural (FF), formic acid (FA) and acetic acid (HAC) in bacterial growth and metabolism, the 10-times diluted synthetic hydrolysate was amended with the three components, either individually or in combination (Figure 1b). In all tested conditions, the growth of Enterobacter sp. LBTM 2 was lower in comparison to $\mathrm{SH} 10$ without inhibitors. However, the inhibition effect of furfural and formic acid on bacterial growth was lower than for the acetic acid. Acetic acid addition caused not only a $70 \%$ reduction on cell biomass production but also a considerable decrease in growth rate. Despite growing lower in the presence of FF and FA, they were consumed during the bacterial growth (Figure 3). Moreover,
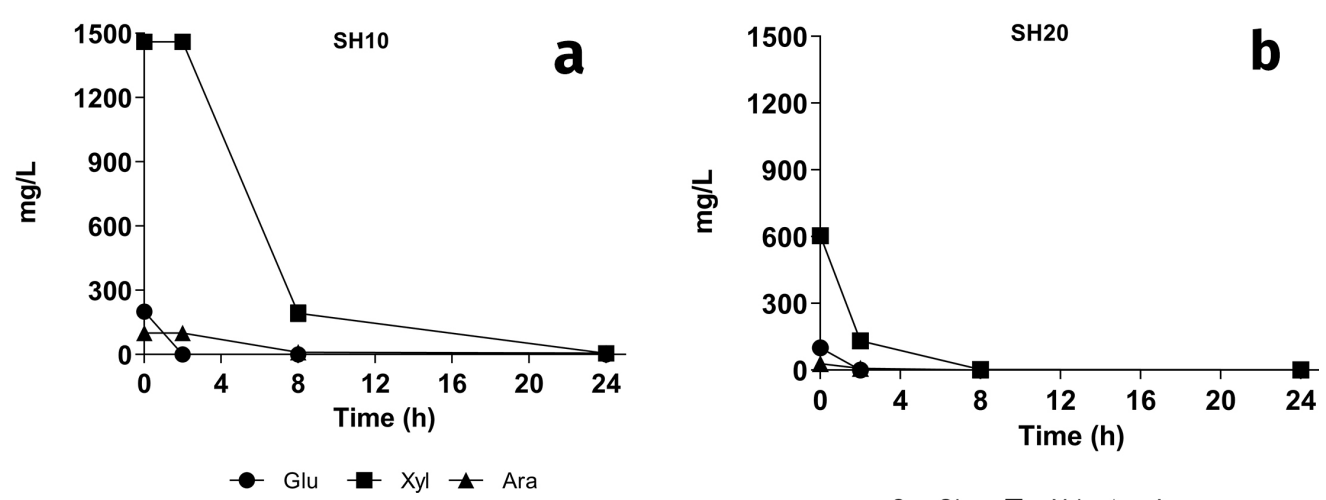

Figure 2. Substrate consumption of Enterobacter sp. LBMT2 in $24 \mathrm{~h}$ batch fermentation on synthetic (SH10, $\mathrm{SH} 20, \mathrm{SH} 30$ being $a, b$ and $c$ respectively) and sugarcane bagasse hemicellulose

- Glu - $\mathrm{Xyl} \_\mathrm{Ara}$

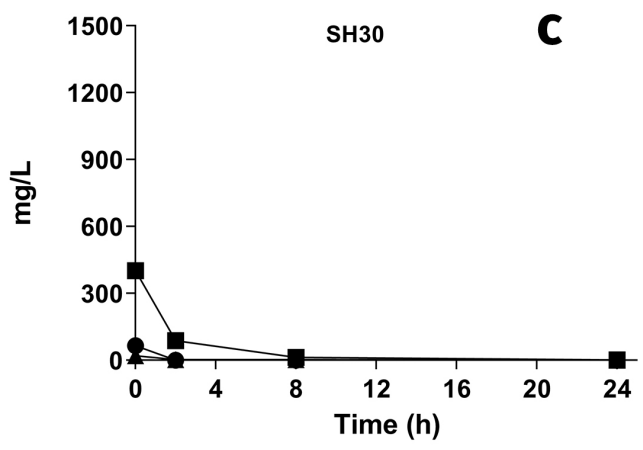

$\mathrm{Xyl} \leftarrow$ Ara

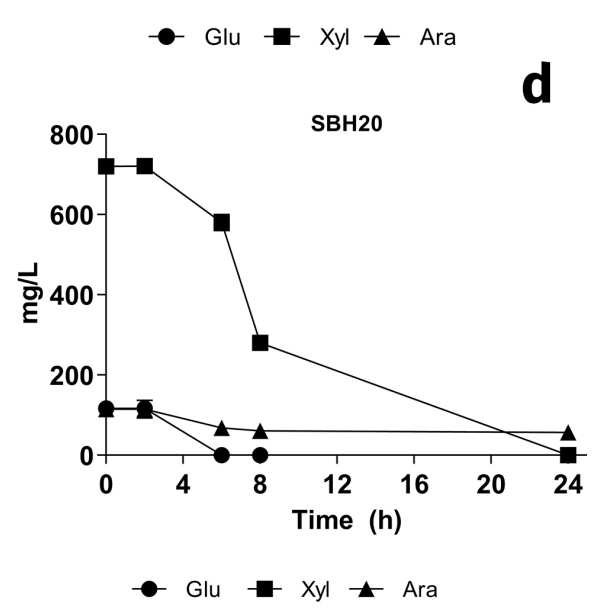

SBH30

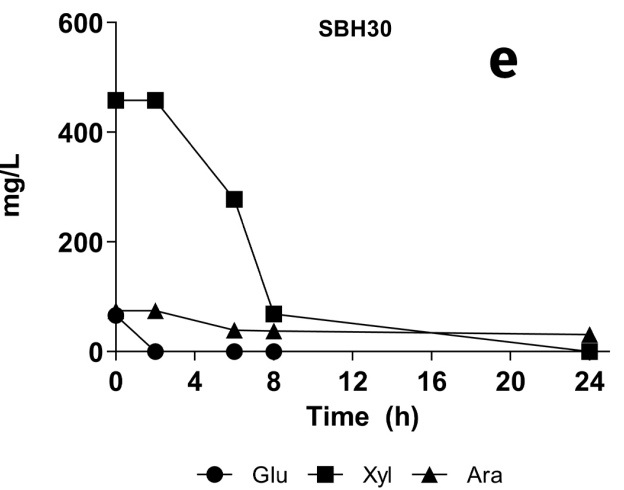
hydrolysate (SBH20, SBH30 being $d$ and $e$ respectively) diluted 10, 20 and 30 times. xyl: xylose; ara; arabinose and glu: glucose. 
in the presence of acetic acid, only $40 \%$ of the xylose was used after a considerable delay in its consumption (after 10h). This information suggests that $0.8 \mathrm{~g} / \mathrm{L}$ of acetic acid has caused an initial inhibition in the absorption of the substrate, and only after a period of adaptation the bacteria started to consume their substrate. A total and irreversible inhibition on bacterial growth was observed when all three compounds were simultaneously added (SH10FF/HAc/FA), suggesting an inability of Enterobacter sp. LBTM 2 to deal with the negative effect of acetic acid (in the presence of furfural and formic acid) during fermentation.

Data on hydrogen production during fermentation of the sugarcane bagasse hemicellulose hydrolysate and synthetic hydrolysate are presented in Figure $4 \mathrm{a}$, while the kinetic parameters calculated by the Gompertz model are shown in Table I. It can be seen that the highest $\mathrm{H}_{2}$ production was obtained for SH2O experiment, which was 2.3-fold higher than SH3O and superior to any SBH experiment. The maximum $\mathrm{H}_{2}$ production obtained for $\mathrm{SH} 2 \mathrm{O}$ was $0.33 \mathrm{mmol}$, which led to the highest yield measured (0.46 $\mathrm{mmolH}_{2} / \mathrm{mol}$ sugar). Regardless of the dilution factor applied to SBH, a similar hydrogen production was observed but lower than those resulting from $\mathrm{SH}$ experiments, as the maximum production was around $0.15 \mathrm{mmol}$ (Table I).

Inhibition of hydrogen production could be verified in the presence of acetic acid (SH1OHAC), in which decreased from 0.21 to $0.10 \mathrm{mmol} \mathrm{H}_{2}$ (Table I, Figure 4b). The addition of $0.3 \mathrm{~g} / \mathrm{L}$ of furfural did not have a significant effect on hydrogen production, only an increase on the lag phase. On the other hand, the presence of $0.4 \mathrm{~g} / \mathrm{L}$ of formic acid promoted a two-fold increase in the $\mathrm{H}_{2}$ production, presumably due to the increment of available substrate for direct hydrogen production, since formic acid was consumed to a great extent during the first $8 \mathrm{~h}$ of experiment (Figure 3).

In order to minimize the inhibition on $\mathrm{H}_{2}$ production, experiments involving the addition of absorbent materials ( 4.2 and $6.2 \%$ of MIP and 3 and $4 \%$ of PAC); these results are presented in Table I. It can be seen that the MIP addition at the SBH2O experiment did not resulted in improvements on $\mathrm{H}_{2}$ production. On contrary, the addition of PAC improved the productivity and yield of hydrogen. The best result was obtained for $3 \%$ addition of PAC, leading to a maximum hydrogen production of $0.32 \mathrm{mmol} \mathrm{H}_{2}$ which was twice higher than that observed with $\mathrm{SBH} 20$ without PAC addition.

Considering the acid metabolites produced during the hydrolysate fermentation, the production of mainly acetic, propionic and formic acids was observed in all experiments (Figures 5 and 6). Ethanol was not generated during the fermentation of hemicellulosic sugars. The VFA concentration was higher in the SBH experiments (concentration up to 1,000 $\mathrm{mg} / \mathrm{L}$ for acetic acid, $800 \mathrm{mg} / \mathrm{L}$ for propionic acid and $700 \mathrm{mg} / \mathrm{L}$ for isobutyric acid, Figures 6a and $6 \mathrm{~b}$ ) when compared to SH. It seems that the additional components of the hydrolysate have contributed not only as carbon source, thereby increasing the production of metabolic acids, but also stimulating an extra metabolic route for producing isobutyric acid. Interestingly, isobutyric acid production was detected at all SBH experiments, but only at the SH experiment where FF was added (SH10-FF, Figure 5e). In this experiment, $1 \mathrm{~g} / \mathrm{L}$ of furfural was added and totally consumed (Figure 3), thus suggesting that isobutyric acid production is probably driven by furfural. 


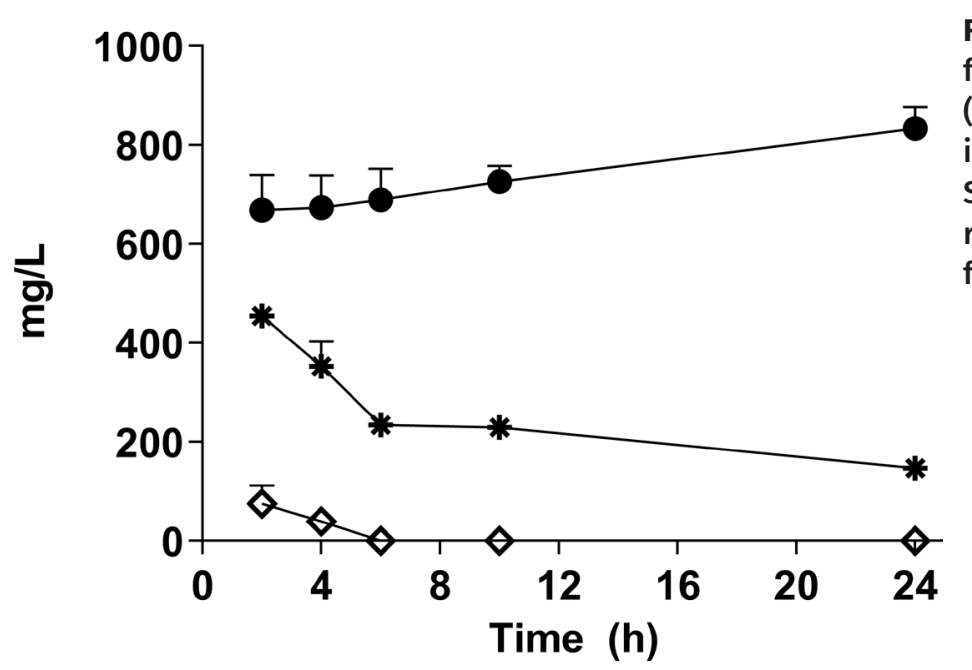

Figure 3. Concentration of furfural (FF), formic acid (FA) and acetic acid (HAC) in the SH10FF, SH10FA and SH10HAc experiments, respectively, along $24 \mathrm{~h}$ of fermentation.
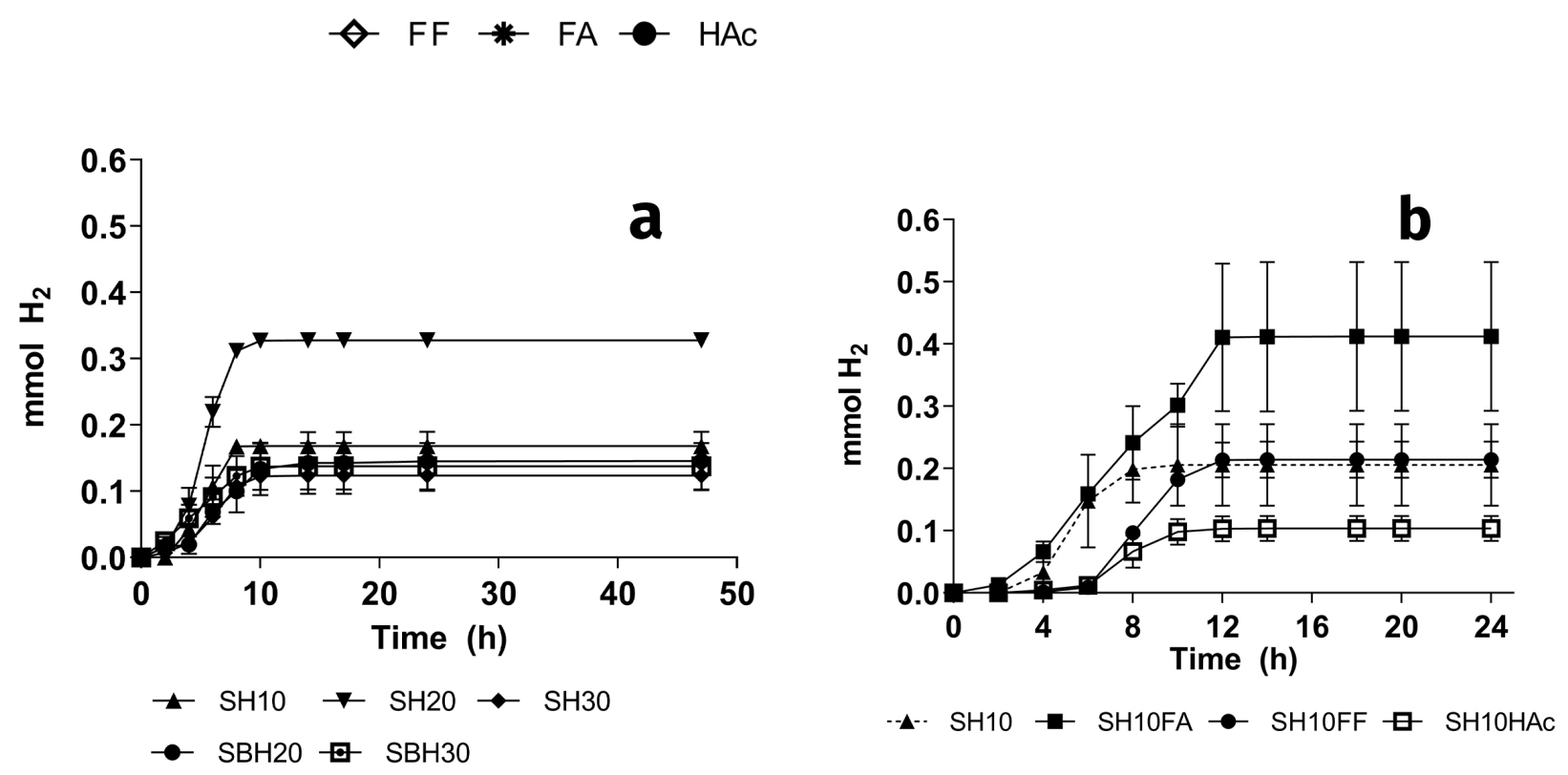

Figure 4. Hydrogen production by Enterobacter sp. LBMT2 during the fermentation of sugarcane hydrolysates. a) synthetic (SH) and sugarcane bagasse hemicellulose hydrolysate (SBH) diluted 10, 20 and 30 times. b) SH10 fermentation with addition of formic acid (FA) furfural (FF) and acetic acid (HAC).

\section{DISCUSSION}

Hemicellulosic hydrolysate obtained by thermal biomass pre-treatment as used in this study may contain compounds such as phenol and furan derivatives, weak acids, and soluble lignin fragments which can be very toxic to microbial activity (Sivagurunatham et al. 2017, Baeta et al. 2016). These toxic effects are related to cell membrane damage, suppression of cell communication and biomass growth, enzyme inactivity (e.g. glycolytic enzymes), sugar uptake and modification of intracellular pH (Lee et al. 2015). Therefore hemicellulose hydrolysate dilutions are usually necessary to ensure proper conditions for fermentation in order to keep low levels of toxicants, while keeping enough substrate to support the bacterial growth. In our results it was observed that at the highest dilution (30-times dilution) of hydrolysate the bacterial 
growth was limited by the low availability of substrate, mainly xylose; whereas at the lowest dilution (10-times dilution) the bacterial growth and growth rate were negatively affected mainly by the high concentration of acetic acid. Mills et al. (2009) have also observed an inhibition of $50 \%$ on the cell growth of Escherichia coli under 0.5 $\mathrm{g} / \mathrm{L}$ of acetic acid, and according to the authors such a decrease in microbial growth may be due to the fact the ATP is exhausted to neutralize the adverse effects of acetic acid, which leads to the bacterial cell having no energy to perform other functions.

The maximum hydrogen production obtained in this work was not observed in the best growth conditions and, like other bacteria,
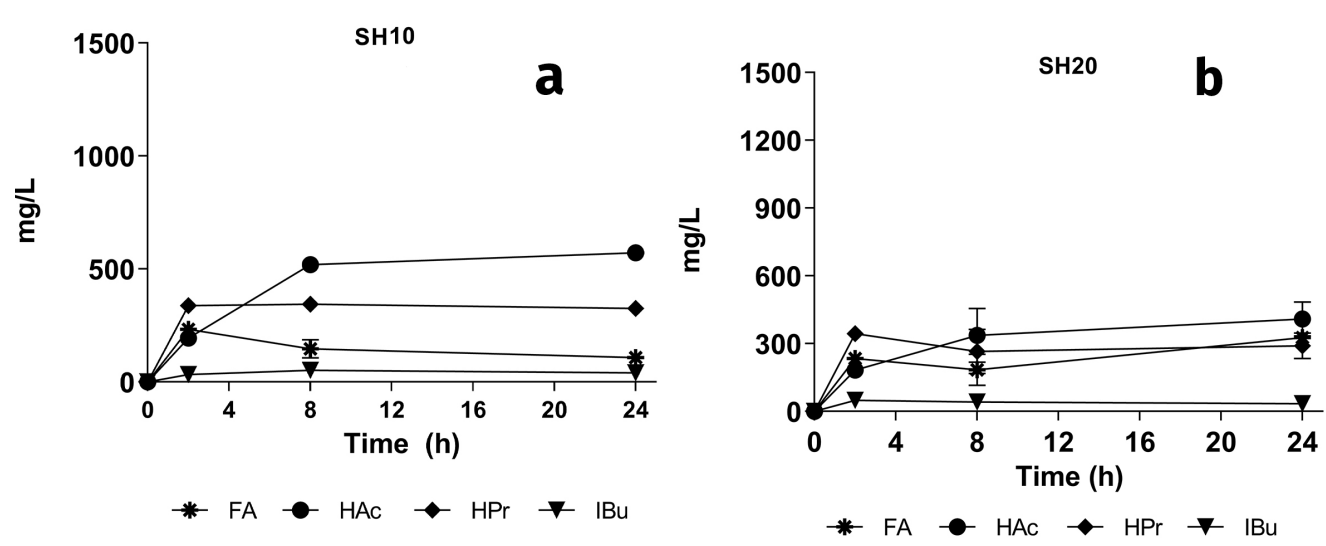

Figure 5.

Concentration of volatile fatty acids (FA formic acid, HAc acetic acid, HPr propionic acid, Ibu isobutyric acid) produced by Enterobacter sp. LBTM2 along $24 \mathrm{~h}$ fermentation of synthetic hydrolysate (SH) diluted 10, 20 and 30 times,with and
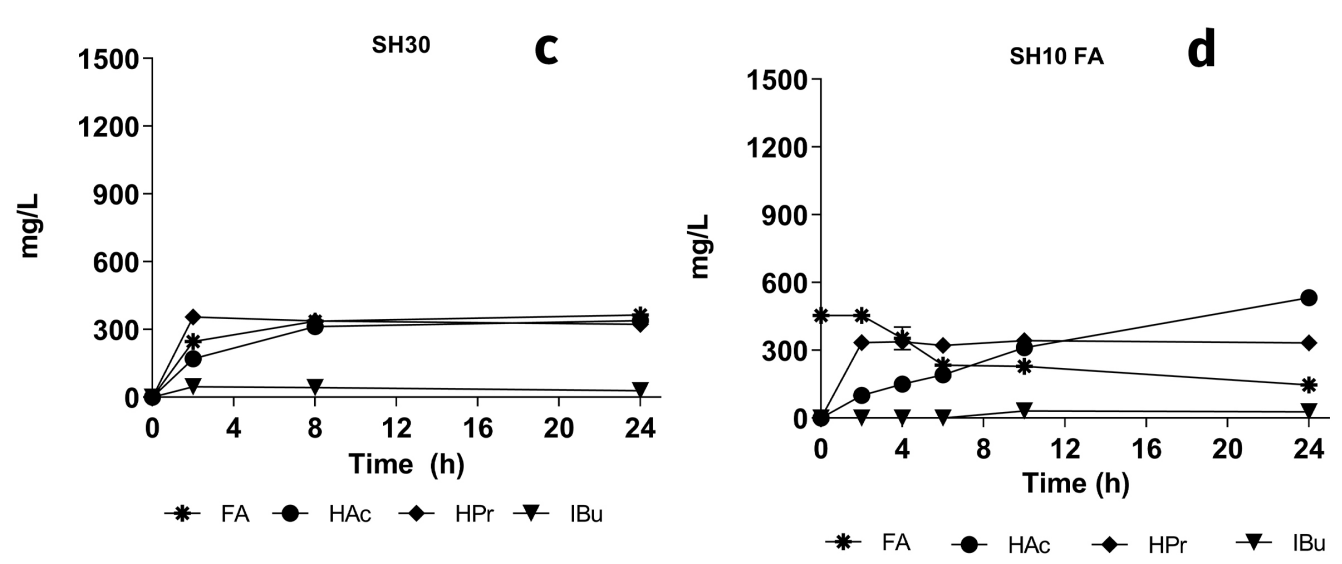
without adition of formic acid (FA), furfural (FF), and acetic acid (HAC) a) $\mathrm{SH} 10$ b) $\mathrm{SH} 20 \mathrm{c}$ ) SH30 d)SH10FA e) SH10FF f) SH10HAC.
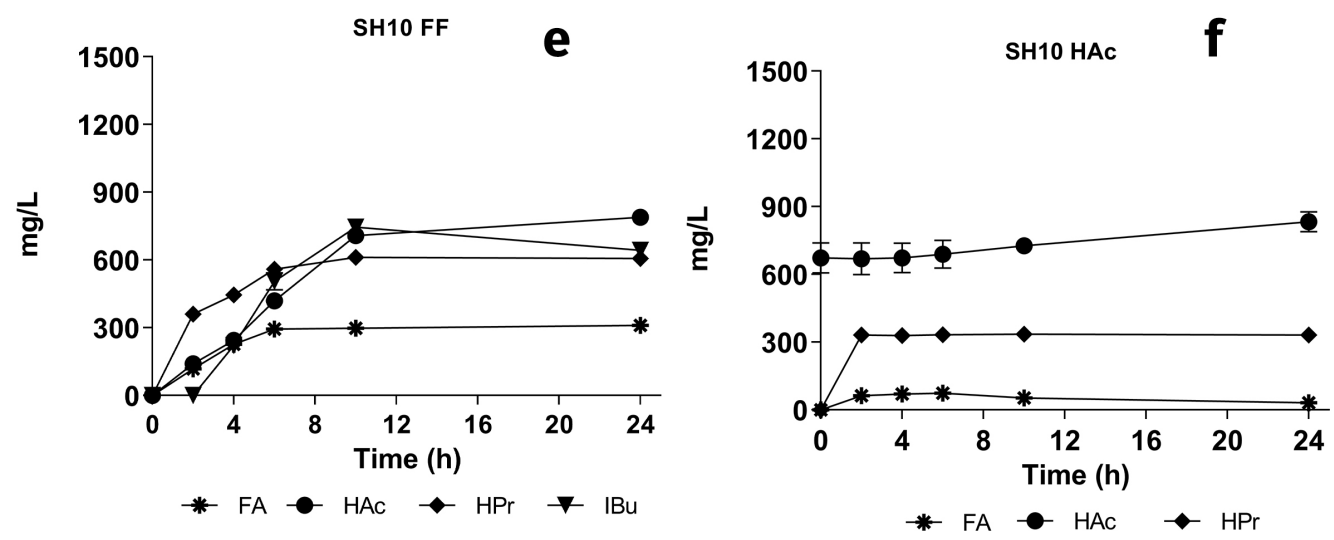
Enterobacter sp. LBTM2 develop their metabolic pathways preferentially for cell growth rather than $\mathrm{H}_{2}$ synthesis (Westermann et al. 2007). This seems to explain the lower production of hydrogen in the best growth condition, i.e., employing SH10. Production of hydrogen by Enterobacter sp. LBTM2 was the highest at the $\mathrm{SH} 20\left(0.33 \mathrm{mmolH}_{2}\right)$ leading to a yield of 0.46 $\mathrm{mmol} \mathrm{H}_{2} / \mathrm{mmol}$ substrate. These results are in the range of those reported by Long et al. (2010) in which Enterobacter CN1 was subjected to xylose and glucose fermentation resulting in yields of 2.0 and $0.64 \mathrm{mmol}_{2} / \mathrm{mmol}$ substrate, respectively. Despite this, hydrogen production by Enterobacter sp. LBTM2 could be increased using strategies such as biomass adaption, as reported by Silva et al. (2019). Therefore adaptation of the Enterobacter sp. LBTM2 by successive contacts of sugarcane bagasse hemicellulose hydrolysate could increase the yield and productivity of hydrogen, and this need to be further addressed.

The yield of hydrogen production is usually related to the metabolic route, being the highest when acetic acid is the main product $\left(\mathrm{C}_{6} \mathrm{H}_{12} \mathrm{O}_{6}\right.$ $\left.+2 \mathrm{H}_{2} \mathrm{O} \rightarrow 2 \mathrm{CH}_{3} \mathrm{COOH}+2 \mathrm{CO}_{2}+4 \mathrm{H}_{2}\right)$ followed by butyric acid $\left(\mathrm{C}_{6} \mathrm{H}_{12} \mathrm{O}_{6} \rightarrow 2 \mathrm{CH}_{3} \mathrm{CH}_{2} \mathrm{CH}_{2} \mathrm{COOH}+2 \mathrm{CO}_{2}\right.$ $+2 \mathrm{H}_{2}$ ) (Nasr et al. 2014). This is probably because hydrogen production is affected by intracellular $\mathrm{NADH}$ levels, since under higher levels of such electron carrier more reduced metabolic products, such as ethanol, lactic acid and propionic acid, are produced (Akobi et al. 2017). This can be seen for propionic acid production in which hydrogen is actually consumed $\left(\mathrm{C}_{6} \mathrm{H}_{12} \mathrm{O}_{6}\right.$ $+2 \mathrm{H}_{2} \rightarrow 2 \mathrm{CH}_{3} \mathrm{CH}_{2} \mathrm{COOH}+2 \mathrm{H}_{2} \mathrm{O}$ ). The major acids detected is this work were acetic, butyric and propionic acids, which were simultaneously produced. When Enterobacter strain LBTM2 was growing in the sugarcane bagasse hemicellulose hydrolysate ( $\mathrm{SBH} 20$ and $\mathrm{SBH} 30$ ) the maximum hydrogen production, as well as the yield of hydrogen production, was lower than the values obtained for the synthetic hydrolysate (SH20). In addition, there was a higher production of acids when the sugarcane bagasse hemicellulose hydrolysate was used. High VFA concentrations generates a decrease in $\mathrm{pH}$, which is one of the major factors that affects the metabolic pathways related to substrate conversion
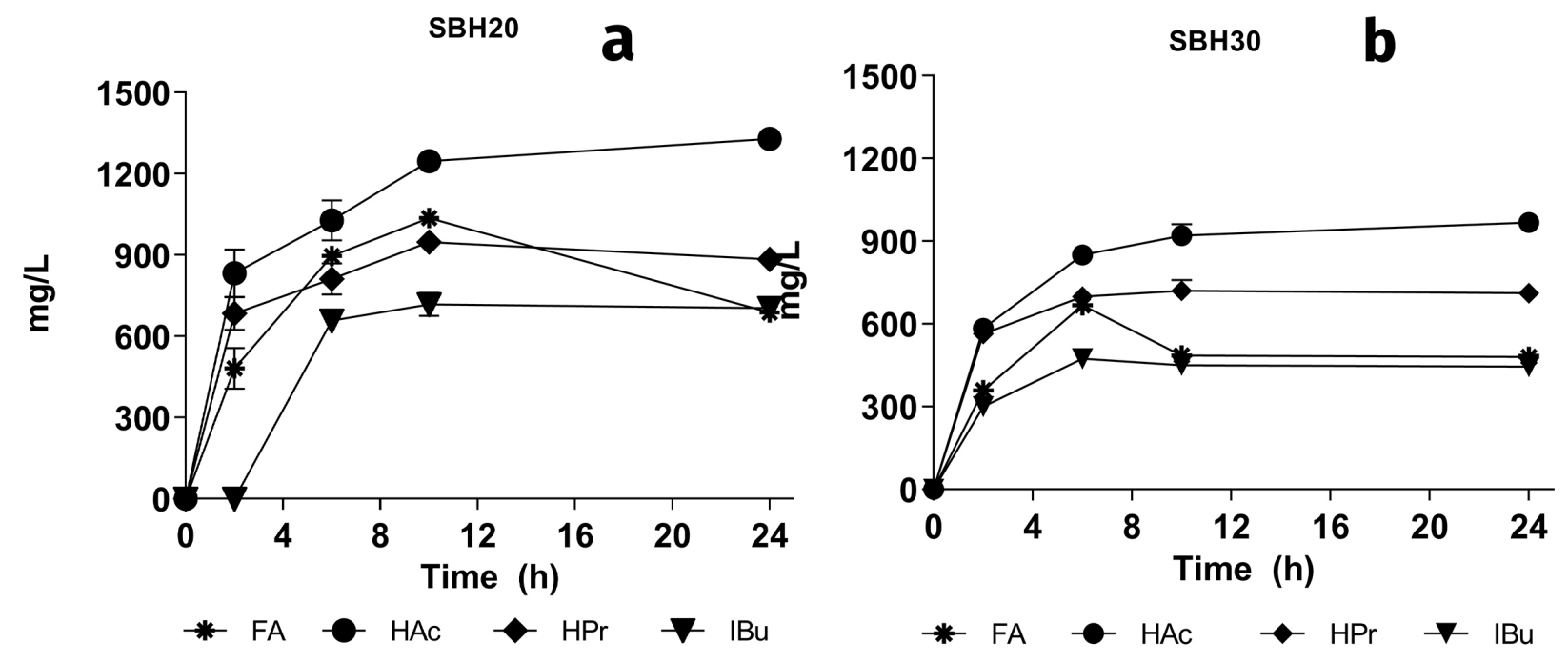

Figure 6. Concentration of volatile fatty acids (FA formic acid, HAc acetic acid, HPr propionic acid, Ibu isobutyric acid) produced by Enterobacter sp. LBTM2 along $24 \mathrm{~h}$ fermentation of sugarcane bagasse hemicellulose hydrolysate (SBH) fermentation a) SBH20 and b) SBH30. 
yield and $\mathrm{H}_{2}$ production (Zhou et al. 2018). Additionally, it was produced isobutyric acid at the SBH experiments and such metabolic shift suggest that extra components of the hydrolysate may drive this metabolism route. In fact, it was observed a production of isobutyric acid at the SH10FF experiment, in which $1 \mathrm{~g} / \mathrm{L}$ of furfural was added. It is unclear if furfural has been totally consumed or biotransformed to a less toxic by-product. Furfural consumption has been reported elsewhere (Zhang et al. 2013, Kumar et al. 2014) and, according to Zhang et al. (2013) Enterobacter sp. FDS8 under anaerobic conditions can metabolize furfural to products such as furfuryl alcohol and furoic acid. Although Zhang et al. (2013) have not investigate isobutyric acid production, probably the presence of the byproduct reported herein suggests a shift in the bacterial metabolism as a response, probably as consequence of the redox balance gear. Nevertheless, the addition of furfural did not affect the hydrogen production in comparison to control experiments. Similarly, Nasr et al. (2014) found that hydrogen production rates and yields were not affected by furfural concentrations in the range of 0.21 to 1.09 $\mathrm{g} / \mathrm{L}$. On the other hand, the impact of furfural addition on hydrogen production and yields was evaluated by Akobi et al. (2017) who reported that a furfural concentration up to $1 \mathrm{~g} / \mathrm{L}$ increased hydrogen production by $19 \%$, while at $4 \mathrm{~g} / \mathrm{L}$ there was a decrease in hydrogen production, which was only re-established when furfural was completely degraded. In the present work it was observed a delay on hydrogen production by $0.3 \mathrm{~g} / \mathrm{L}$ furfural addition, indicating that hydrogen accumulation started only when when furfural was no longer present in the medium. Among the hydrolysate toxicants evaluated, the formic acid had a stimulatory effect for hydrogen production. In fact, some studies have reported a positive effect of formic acid on hydrogen production, but it depends on its concentration. For instance, Kumar et al. (2014) showed that concentrations of formic acid up to $5 \mathrm{~g} / \mathrm{L}$ increased hydrogen yield but that at 12.5 $\mathrm{g} / \mathrm{L}$ it inhibited the hydrogen production by $50 \%$. On the other hand, Joo et al. (2016) observed an inhibition of Enterobacter aerogenes growth in the presence of $3 \mathrm{~g} / \mathrm{L}$ of formic acid in the xylose fermentation. It is known that for several members of Enterobacteriacea family, the formic acid is a direct substrate of the formatehydrogen-lyase complex which breaks down formate and generates $\mathrm{H}_{2}$ and $\mathrm{CO}_{2}$ (Sinha et al. 2015, Bellido et al. 2011). As observed, formic acid and furfural added alone had a little impact on the bacterial growth; in fact they were used as additional source electrons for hydrogen production. However when formic acid and furfural were added together with acetic acid, the bacterial growth was strongly and permanently inhibited. It has been hypothesized that the combination of these toxic compounds has a more negative impact on the microbial growth, as well as on yield of fermentative products, when compared to the effect of each one individually. This was also observed by Bellido et al. (2011) when applied acetic acid, furfural and hydroxymethylfurfural together which caused inhibition on Pichia stipitis for ethanol production. Munoz-Pàez et al. (2018) also observed a synergic effect of hydrolysate toxicants when microorganisms were exposed simultaneously to these compounds. Considering that the presence of acetic acid has a strong effect on the Enterobacter sp. LBTM2 growth, it was speculated that the removal of acetic acid from the fermentative bulk could improve bacterial growth and therefore $\mathrm{H}_{2}$ production. For this, the application of two adsorbents (MIP and PAC) was tried. The MIP chosen to be tested in this work had been previously synthesized using isovaleric acid as template, according 
to Tonucci et al. (2019). This acid has a larger (5c) and more complex carbon chain (due to branching) than the others, thus resulting in an MIP that could be applied to remove all the main VFAs accumulating in anaerobic digestion. Indeed, the results published by Tonucci et al. (2019) showed that such material has a high adsorption capacity for all VFAs, particularly for acetic acid with qmax value of $209 \mathrm{mg} / \mathrm{g}$. However, unexpectedly, the experiments carried out with MIP did not reveal an increase in hydrogen production. This probably occurred due to the low mass of the MIP used (0.09 g). Considering the qmax value reported earlier, the removal of $1 \mathrm{~g} / \mathrm{L}$ of acetic acid would require a theoretical MIP mass of 4.7 grams. Therefore, it was assumed that the MIP mass used, only $2 \%$ of the required value based on theoretical adsorption capacity, was not sufficient to improve the hydrogen production. In addition, MIP is specific for VFA adsorption so the aldehydes (FF and 5-HMF) present in the medium remained in the bulk solution and might have also contributed for inhibiting hydrogen production. On the contrary, the addition of PAC at the SBH2O experiment improved the productivity and yield of hydrogen. The best result was obtained by the addition of $3 \%$ PAC, leading to a maximum hydrogen production of $0.32 \mathrm{mmol}_{2}$, which was two times higher than that observed with SBH2O without PAC addition. Guo et al. (2013) have found that among several methods for hydrolysate detoxification, the activated carbon exhibited better results by removing $6 \%$ furfural, $72 \%$ acetic acid and $61 \%$ formic acid. PAC is frequently used in hydrolysate fermentation because of its high capacity to adsorb organic compounds and for not compromising sugar levels due to its low affinity to such polar substrates (Chandel et al. 2013, Kamal et al. 2011, Soleimani et al. 2015). In fact, the application of PAC in the fermentation has improved the hydrogen production by doubling productivity of the reactor.

This improvement probably resulted not only from adsorption of acetic acid but also other contaminants. However, a complete experiment monitoring have to be conducted in order to elucidate the role of PAC to the hydrogen fermentation environment.

\section{CONCLUSIONS}

The comparative dark fermentation using synthetic and sugarcane bagasse hemicellulose hydrolysate revealed that hydrogen production by Enterobacter sp. LBTM2 is driven not only by hemicellulosic sugars but also by the formic acid generated during the hydrothermal pretreatment of sugarcane bagasse. On the other hand, furfural did not impact the hydrogen productivity but had to be first metabolised to ensure the production of hydrogen. Nevertheless the presence of furfural on the hemicellulosic hydrolysate induced volatille faty acids accumulation, particularly the isobutyric acid in the bulk liquid. In a more pronounced action, the acetic acid present in the hemicellulosic hydrolysate has decreased the xylose uptake and bacterial growth, thereby compromising the productivity and yield of hydrogen. The addition of powdered activated carbon (PAC) to the fermentative bulk liquid has improved the hydrogen production. PAC is a relatively low-cost and easy-to-use alternative to remove toxic compounds from lignocellulosic hydrolysates, thus reducing the dilution factors and increasing the productivity and yield of hydrogen production.

\section{Acknowledgments}

This study was financed in part by the Coordenação de Aperfeiçoamento de Pessoal de Nivel Superior (CAPES) - Finance Code 001, Fundação de Amparo à Pesquisa 
do Estado de Minas Gerais (Fapemig, Grant TEC APQ 03502-16), Universidade Federal de Ouro Preto (UFOP, grant 23109.003268/2017-47) and Conselho Nacional de Desenvolvimento Científico e Tecnológico (CNPq - Grant 455609/2014-4).

\section{REFERENCES}

AKOBI C, HAFEZ H \& NAKHLA G. 2017. Impact of furfural on biological hydrogen production kinetics from synthetic lignocellulosic hydrolysate using mesophilic and thermophilic mixed cultures. Int J Hydrogen Energy 42: 12159-12172.

BAETA BEL, LIMA DRS, ADARME OFH, GURGEL LVA \& AQUINO SF. 2016. Optimization of sugarcane bagasse autohydrolysis for methane production from hemicellulose hydrolyzates in a biorefinery concept. Bioresour Technol 200: 137-146.

BIELEN AA, VERHAART MR, VAN DER OOST J \& KENGEN SW. Biohydrogen Production by the Thermophilic Bacterium Caldicellulosiruptor saccharolyticus: Current Status and Perspectives. Life (Basel) 2013: 52-85.

BELLIDO C, BOLADO S, COCA M, LUCAS S, GONZÁLES-BENITO G \& GARCIA-CUBERO MT. 2011. Effect of inhibitors formed during wheat straw pretreatment on ethanol fermentation by Pichia stipitis. Bioresour Technol 102(23): 10868-10874.

CHANDEL AK, DA SILVA SS \& SINGH OV. 2013. Detoxification of Lignocellulose Hydrolysates: Biochemical and Metabolic Engineering Toward White Biotechnology. Bioenerg Res 6: 388-401.

DE BHOWMICK G, SARMAH AK \& SEN R. 2018. Lignocellulosic biorefinery as a model for sustainable development of biofuels and value-added products. Bioresour Technol 247: 1144-1154.

DE SÁ LRV, FABER MO, SILVA AS, CAMMAROTA MC \& FERREIRALEITÃO VS. 2020. Biohydrogen production using xylose or xylooligosaccharides derived from sugarcane bagasse obtained by hydrothermal and acid Pretreatments. Renew. Energy 146: 2408-2415.

GONZALES RR, SIVAGURUNATHAN P, PARTHIBAN A \& KIM SH. 2016. Optimization of substrate concentration of dilute acid hydrolyzate of lignocellulosic biomass in batch hydrogen production. Int Biodeterior Biodegrad 113: 22-27.

GUO X, CAVKA A, JONSSON LJ \& HONG F. 2013. Comparison of methods for detoxification of spruce hydrolysate for bacterial cellulose production. Microbial Cell Factories 12(1): 1-14.
JOO J, LEE SJ, YOO HY, KIM Y, JANG M, LEE J \& PARK C. 2016. Improved fermentation of lignocellulosic hydrolysates to 2, 3-butanediol through investigation of effects of inhibitory compounds by Enterobacter aerogenes. Chem Eng J 306: 916-924.

KAMAL SMM, MOHAMAD NL, ABDULLAH AGL \&ABDULLAH N. 2011. Detoxification of sago trunk hydrolysate using activated charcoal for xylitol production. Procedia Food Sci 1: 908-913.

KUMAR G, CHEON HC \& KIM SH. 2014. Effects of 5-hydromethylfurfural, levulinic acid and formic acid, pretreatment byproducts of biomass, on fermentative $\mathrm{H}_{2}$ production from glucose and galactose. Int J Hydrogen Energ 39: 16885-16890.

LEE SJ, LEE JH, YANG X, KIM SB, LEE JH \& YOO HY. 2015. Phenolic compounds: Strong inhibitors derived from lignocellulosic hydrolysate for 2,3-butanediol production by Enterobacter aerogenes. Biotechnol J 10: 1920-1928.

LONG C, CUI J, LIU Z, LIU Y, LONG M \& HU Z. 2010. Statistical optimization of fermentative hydrogen production from xylose by newly isolated Enterobacter sp. CN1. Int J Hydrogen Energ 35(13): 6657-6664.

MILLSTY, SANDOVAL NR \& GILL RT. 2009. Cellulosic hydrolysate toxicity and tolerance mechanisms in Escherichia coli. Biotechnol Biofuels 2(26): 1-11.

MUNOZ-PÀEZ KM, ALVARADO-MICHI EL, BUITRÓN G \&VALDEZ-VASQUEZ I. 2018. Distinct effects of furfural, hydroxymethylfurfural and its mixtures on dark fermentation hydrogen production and microbial structure of a mixed culture. Int J Hydrogen Energ 1-9.

NASR N, GUPTA M, ELBESHBISHY E, HAFEZ H, EL NAGGAR MH \& NAKHLA G. 2014. Biohydrogen production from pretreated corn cobs. Int J Hydrogen Energ 39: 19921-19927.

NISSILÄ ME, LAY CH \& PUHAKKA J. 2014. Dark fermentative hydrogen production from lignocellulosic hydrolyzates A review. Biomass Bioner 67: 145-159.

SHAHAR T, TAL N \& MANDLER D. 2016. Molecularly imprinted polymer particles: Formation, characterization and application. Colloids Surf A Physicochem Eng Asp 495: 11-19.

SILVA FG, FERREIRA-LEITÃO VS \& CAMMAROTA MC. 2019. Strategies for Increasing the Biohydrogen Yield in Anaerobic Fermentation of Xylose. Environ Nat Resour J 9: $32-40$.

SINHA P, ROY S \& DAS D. 2015. Role of formate hydrogen lyase complex in hydrogen production in facultative anaerobes. Int J Hydrogen Energ 40(29): 8806-8815. 
SIVAGURUNATHAN P, KUMAR G, MUDHOO A, RENE ER, SARATALE GD \& KOBAYASHI T. 2017. Fermentative hydrogen production using lignocellulose biomass: An overview of pretreatment methods, inhibitor effects and detoxification experiences. Renew Sust Energ Rev 77: 28-42.

SOLEIMANI M, TABIL L \& NIU C. 2015. Adsorptive Isotherms and the Removal of Microbial Inhibitors in a Bio-based Hydrolysate for Xylitol Production. Chem Eng Commun 202(6): 787-798.

TARLEY CRT, SOTOMAYOR MDPT \& KUBOTA LT. 2005. Biomimetic polymers in analytical chemistry. Part 1: preparation and applications of MIP (Molecularly Imprinted Polymers) in extraction and separation techniques. Quim Nova 28: 1076-1086.

TONUCCI MC, FIDÉLIS ALS, BAETA BEL, TARLEY CRT \& DE AQUINO SF. 2019. Influence of synthesis conditions on the production of molecularly imprinted polymers for the selective recovery of isovaleric acid from anaerobic effluents. Polym Int 68: 428-438.

WESTERMANN P, JØRGENSEN B, LANGE L, AHRING BK \& CHRISTENSEN CH. 2007. Maximizing renewable hydrogen production from biomass in a bio/catalytic refinery. Int J Hydrogen Energ 32: 4135-4141.

ZHANG D, ONG YL, LI Z \& WU JC. 2013. Biological detoxification of furfural and 5-hydroxyl methyl furfural in hydrolysate of oil palm empty fruit bunch by Enterobacter sp. FDS8. Biochem Eng J 72: 77-82.

ZHOU M, YAN B, WONG JW \& ZHANG Y. 2018. Enhanced volatile fatty acids production from anaerobic fermentation of food waste: A mini-review focusing on acidogenic metabolic pathways. Bioresour Technol, p. 68-78.

\section{How to cite}

CAMPOS IM, ZOREL JA, MENEGATTO M, SILVA F, ADARME OFH, TONUCCI M, BAÊTA BEL, AQUINO SF \& SILVA SQ. 2021. Hydrogen production by Enterobacter sp. LBTM 2 using sugarcane bagasse hemicellulose hydrolysate and a synthetic substrate: understanding and controlling toxicity. An Acad Bras Cienc 93: e20201679. DOI 10.1590/00013765202120201679.

Manuscript received on October 20, 2020;

accepted for publication on February 27, 2021

\section{IVON M. CAMPOS ${ }^{1}$}

https://orcid.org/0000-0001-9343-0808

JOSE AUGUSTO ZOREL

https://orcid.org/0000-0003-1088-5570

\section{MARILIA MENEGATTO ${ }^{1}$}

https://orcid.org/0000-0002-4996-0411

\section{FLAVIANE SILVA}

https://orcid.org/0000-0003-3433-8969

OSCAR F.H. ADARME ${ }^{2}$

https://orcid.org/0000-0002-4203-4642

\section{MARINA TONUCCI ${ }^{2}$}

https://orcid.org/0000-0002-2467-1584

\section{BRUNO E.L. BAÊTA2}

https://orcid.org/0000-0003-2327-0559

\section{SÉRGIO F. AQUINO 2}

https://orcid.org/0000-0001-6058-3218

\section{SILVANA Q. SILVA'}

https://orcid.org/0000-0002-0077-4669

${ }^{1}$ Universidade Federal de Ouro Preto, Departamento de Ciências Biológicas, Laboratório de Biologia e Tecnologia de Microrganismos, Campus Morro do Cruzeiro, s/n, 35400-000 Ouro Preto, MG, Brazil

${ }^{2}$ Universidade Federal de Ouro Preto, Departamento de Química, Laboratório de Química Tecnológica e Ambiental, Campus Morro do Cruzeiro, s/n, 35400-000 Ouro Preto, MG, Brazil

Correspondence to: Silvana de Queiroz Silva

E-mail: silvana.silva@ufop.edu.br

\section{Author contributions}

I.M.C: acquisition, analysis and interpretation of data; J.A.Z, M.M, and F.S.: experiment monitoring and chromatographic analyses; O.F.H.A: PAC application; M.T.: MIP providing; B.E.L.B: SHB production; S.F.A written assistance; and S.Q.S: grant, written and discussion.

\section{(cc) $\mathrm{BY}$}

